\title{
Study on water quality improvement capacity by using floating bed made of fiber packing
}

\author{
Peng Sun ${ }^{1, ~ a}$, Kangping Cui ${ }^{2, b}$, Honghan Chen ${ }^{1, c}$ \\ ${ }^{1}$ School of water resources \& Environment, China University of Geosciences, Beijing, 100083 China \\ ${ }^{2}$ School of Resources and Environmental Engineering, Hefei University of Technology, Hefei \\ 230009, China \\ apiaofeixue_sp@163.com, ${ }^{\mathrm{b}}$ cuikangping@163.com, ${ }^{\mathrm{C}}$ chenhonghan@163.com
}

Keywords: ecological floating bed, polluted water, fiber packing, water quality improvement

\begin{abstract}
Three kinds of floating beds of aquatic plants floating bed with new types of fiber packing (A), aquatic plants floating bed with elastic packing (B), aquatic plants floating bed were established. The effect on the pollutant removal efficiency in wastewater from farmer household tourism at shiyanbaierhe was examined and the contaminant removal characteristic by different units was also analyzed. The results showed that floating bed system (A) showed very high removal efficiencies with respect to $\mathrm{TN}, \mathrm{NH}_{4}{ }^{+}-\mathrm{N}, \mathrm{COD}_{\mathrm{cr}}$ and TP. Compared to floating bed (B) and (C), $\mathrm{TN}$, $\mathrm{NH}_{4}{ }^{+}-\mathrm{N}, \mathrm{COD}_{\mathrm{cr}}$ and TP removal efficiencies of A rapidly increased at $15.3 \% 、 33.2 \% ; 18.8 \% 、 34.7 \%$; $16.4 \% 、 30.6 \% ; 18.3 \% 、 41.3 \%$ respectively while significantly higher than in black control with $\mathrm{p}<0.05$. It showed the fiber packing was suitable for wastewater treatment which better than elastic space packing because of its excellent property.
\end{abstract}

\section{Introduction}

Ecological floating bed becomes an eco-treatment technology which is widely used in many places in consideration of its low cost, easy operation and better landscape benefit. Our country bring in floating bed from 1991, and now it is applied to different sewage treatmentafter many years continuous efforts [1].

Traditional ecological floating bed purification ability is limited because of its simplicity and monotonicity. Numerous studies have focused on the purification ability of aquatic plant and bionic aquatic plants are also one of research keys for many scholars [2]. There are rare reports about the influence of packing structure on the treatment effort. In the study, we build floating bed with anewtypes of fiber packing and elastic packing. The differences of water quality index processing ability of water are studied, so we can selected a better system, thereby providing reference for purifying water quality in ShiyanBaier River and surrounding areas, constructing, promoting and applying plant ecological floating bed system.

\section{Materials and methods}

\subsection{Experiment materials}

The calamusis used as experimental plant, after the plant is used land seedlingcultivation. The packing of floating bed is adopteda new types of fiber packing and elastic solid packing. The experimentalwater is collected from river way of Baierhe,seasonaldifference of water quality isgreat. The experimentis in order to better simulate sewage discharged into Baierhe at the start, the corresponding artificial water distributionis supplemented on the basis of the river, the water quality regulation as shownin Table 1.

Table1 The Water Quality for Experiments

\begin{tabular}{ccccc}
\hline parameter & $\mathrm{TN} / \mathrm{mg} \cdot \mathrm{L}^{-1}$ & $\begin{array}{c}\text { ammonia nitrogen / } \\
\mathrm{mg} \cdot \mathrm{L}^{-1}\end{array}$ & $\begin{array}{c}\text { total phosphorus / } \\
\mathrm{mg} \cdot \mathrm{L}^{-1}\end{array}$ & $\begin{array}{c}\mathrm{COD}_{\mathrm{cr}} \\
\mathrm{mg} \cdot \mathrm{L}^{-1}\end{array}$ \\
\hline range & $19.35 \sim 25.75$ & $17.63 \sim 21.42$ & $3.5 \sim 4.5$ & $56 \sim 82$ \\
\hline
\end{tabular}




\subsection{Experimental methods}

Experimental container is $100 \mathrm{~cm}$ long, $80 \mathrm{cmwideand} 60 \mathrm{~cm}$ highwater tank. The floating bed frame adopts polyethylene foam board; specificationis $35 \mathrm{~cm} \times 35 \mathrm{~cm}$. Experimentis set up four groupstreatment, each group treatmentis set up two repetition, respectively,are the composite floating bed $\mathrm{A}$, composite floating bed $\mathrm{B}$, the traditional floating bed $\mathrm{C}$ and blank control. Among them, the composite floating bedA is planting calamus, fiber packing was hangedbeneath it; the calamusis planted over composite floating bed $\mathrm{B}$, elastic three-dimensional packing hanged was hanged beneath it; the floating bed $\mathrm{C}$ only grows plant, without packing beneath it;with blank control. Three kinds of floating beds all grow2calamus, the coverage rate of floating bed is about $30 \%$. Packing is about $40 \mathrm{~cm}$ in length;the density is $30 \mathrm{bunch} / \mathrm{m}^{2}$.

\subsection{Sample collection and date analysis}

The determination of water quality indexes TN, TP, ammonia nitrogen and chemical oxygen demand (cod) according to "Water and Wastewater Monitoring Analysis Method".Data is adopted SPSS 17.0, Microsoft Excel 2010 and SigmaPlot 12.5software for treatment, and the One-Way ANONY is used to analyze significant differences ofdifferent treatment group.

\section{The results and discussion}

\section{1 removal effect analysis of nitrogen in water body}
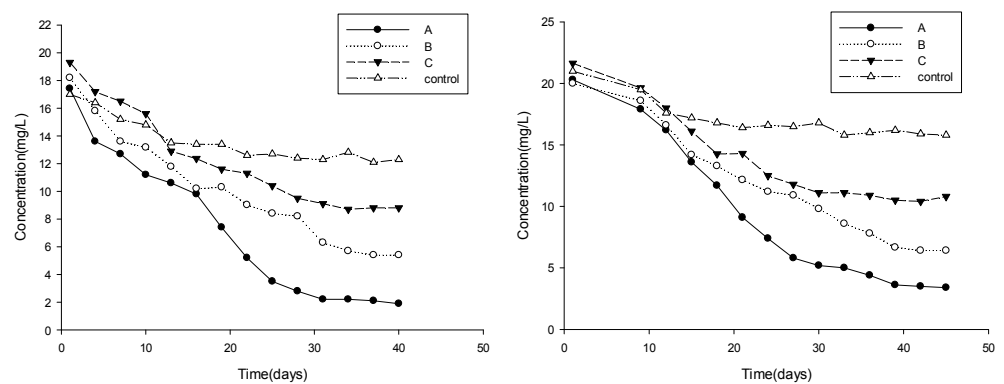

Fig. 1 The change curve of $\mathrm{NH}_{4}{ }^{+}$-NFig. 2 The change curve of TN

As shown in Fig.1, ammonia nitrogen removal effect of A, B and Cthree sets of systems is better. Three sets of system for ammonia nitrogen removal rate are $89.1 \%, 70.3 \%$ and $54.4 \%$ respectively, A system is significantly different with the blank control $(p<0.05)$, it have obviously reduction function for ammonia nitrogen in wastewater. A system is better than any other system, because system internals has more rich microbes, it makes nitrifying bacteria multiply rapidly and nitration reactionoccurred. Meanwhile, aeration beneath the bottom of floating bed make the dissolved oxygen abundant in water, it provides a necessary condition for nitration. In addition, the plant has a certain amount of absorption for ammonia nitrogen; the plant can directly utilizefree ammonia nitrogen in water to synthesize needed material itself, to a certain extent, it reduces the concentration of ammonia nitrogen in water.

As shown in Fig.2, A, B and C three groupstreatment system has obvious removal effect for total nitrogen in sewage, A system is significant different from the control group $(p<0.05)$. In experimental early, the total nitrogen concentration of different treatment system is between 20 $\mathrm{mg} / \mathrm{L} \sim 22 \mathrm{mg} / \mathrm{L}$, with the processing of experiment, the concentration of total nitrogen decreased significantly, there is a rapid decline stage in the early stage, it is likely to be caused by nitrogen particles adsorbed and intercepted, medium-term have small fluctuation, it may be because the plants withered and decayed, sedimentrelease nitrogen in water, the late tends to stabilize, after experiment is over, the three groups floating beds have $83.3 \%, 68 \%$ and $50.1 \%$ removal rate to TN, it is far higher than the control group.

It can be seen from the above two figure, A system has stronger removalability for nitrogen, because: (1) the packing of A floating bed system has good interception function, it can intercept and absorb particles with nitrogen in water, meanwhile, the wide area fully expanded the stereo space, make up lack of microbe quantity and filtration functiondeficiencyand other faultscaused by short roots, as the increase of microbe species and quantity in the internal system, biofilms 
gradually matures, increase of nitrifying bacteria with longer generation cycle provides basic conditions for nitrification of ammonia nitrogen, it ensure the efficient removal of ammonia nitrogen. (2) The packing structure in the A floating bed system provides more attachment sites, make internal biofilm growpieces-link, extracellular polymer made microbe with mutually beneficial relationship more closer, formed including bacteria, fungi and algae (in the light conditions), protozoan, metazoan interior microbesymbiont, thus forming a kind of complex and stable ecological system, it makes theaerobic bacteria, anaerobic bacteria and facultative bacteriain systematic interior can simultaneously nitrification-denitrificationin different space, improve the nitrogen removalefficiency.

\subsection{The removal efficiency analysis of water body TP}

It is known from Fig.3, the concentration of total phosphorus from the initial $4.1 \mathrm{mg} / \mathrm{L}, 4.3 \mathrm{mg} / \mathrm{L}$ and $4.5 \mathrm{mg} / \mathrm{L}$ down to the water $0.6 \mathrm{mg} / \mathrm{L}, 1.4 \mathrm{mg} / \mathrm{L}$, and $2.3 \mathrm{mg} / \mathrm{L}$, removal rate are $83.8 \%, 65.5 \%$ and $42.5 \%$ respectively. A system is significantly different from blank treatment $(\mathrm{p}<0.05)$, compared with the traditional floating bed B system, it also has high removal rate. Generally speaking, the removal total phosphorus includes plant absorption, physical settlement, the root and packing interception, matrix adsorption and microbial degradation[3]. In the initial stage of experiment, decline rate of total phosphorus is faster by sedimentation and interception effect, lead to a drop in phosphorus particles. Higher phosphorusis removed in system A, this is because combined action outcome of plant absorption, packing interception, sedimentation and microbe.Among them, the plant cannot directly absorb and make use of organ phosphorus and phosphate with poor solubility, it is only by microbes transformed into dissolved phosphate, then can be absorbed by plants and microbe, phosphorusabsorption is low, phosphorus removal effect is not obvious, net flocculent structure of composite systempacking form enriched microbial species and quantity, especially the existence of abundant phosphorus, it makes phosphorus content continuallyreduce in the system and superior to other groups of experiments. And aeration may has a favorable impact on total phosphorus removing by precipitation, adsorption and adhesion and other effects, so as to promote the removal effect of total phosphorus [4].
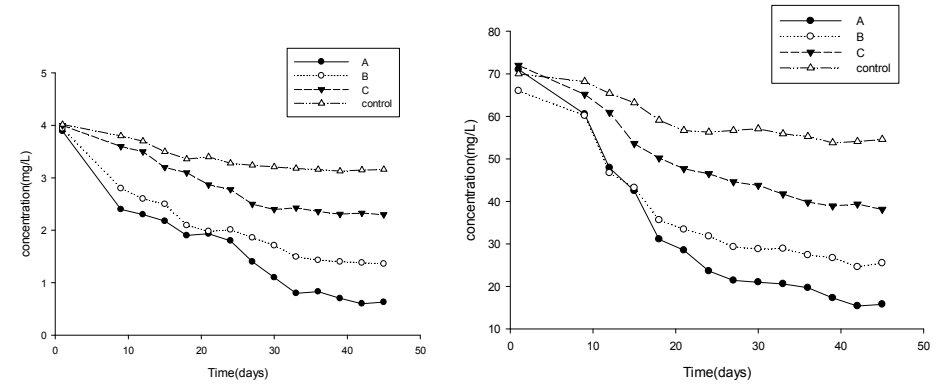

Fig.3 The change curve of TPFig.4 The change curve of COD

\subsection{The removal effect analysis of water chemical oxygen demand (cod)}

It is known from Fig.4, the content of CODcrall appeared a decreasing trend. At the end of the experiment, waterCODcr removal rate of A, B, C and blank four setsystem were $77.8 \%, 61.4 \%, 47 \%$ and $61.4 \%$. A system has obvious reduction effect on COD, and the control groupsare significantly different. The degradation of organic matter in water is affected by water temperature, dissolved oxygen, microbial species, quantity and other factors,it was degraded by anaerobic degradation, anaerobic degradation and aerobic degradation and different ways. Due to special structureof packing, the system Asignificantly increased the number and variety of microbe in the system, these microbe degradeorganics in wastewater by its own metabolism, the concentration is reduced; degradation effect of plant on COD is more limited, they rely mainly on enrichedmicrobe on the root to realize the degradation. It can be seen from comprehensive analysis that A floating bed system has better purification effect onsewage with low concentration COD. 


\section{Conclusions}

Ecological floating beds with news types of packing have better purification effect compare with traditional floating bed. Between the two, fiber packing floating bed is more advantage to remove pollutants from water. The removal rate of $\mathrm{COD}_{\mathrm{cr}}, \mathrm{NH}_{4}{ }^{+}-\mathrm{N} 、 \mathrm{TN}$ and $\mathrm{TP}$ are $77.8 \%, 89.1 \% 、 83.3 \%$ 、 $83.8 \%$ respectively.A system is significantly different from blank treatment $(\mathrm{p}<0.05)$

Composite floating bed increases the stability of the system and expands the stereo space, which can effectively reduce the impact on floating bed system in condition of the factor of plants decay. It has the advantage of stable and good removal effect.

Influence of season on floating-bed is not considered in the test process. The influence of climate environment factor on effect of treatment is increased in subsequent study, and thereby the composite floating bed with fiber packing can be further screened in details.

\section{Acknowledgements}

This work was financially supported by the Major projects of water pollution control and management technology (NO.2012ZX07205-002).

\section{References}

[1] Sun L E, Liu Y, Jin H. Nitrogen removal from polluted river byenhanced floating bed grown canna. Ecological Engineering. Vol.35 (2009) No.1, p. 135-140.

[2] Gruber N, Galloway J N. An earth-system perspective ofthe global nitrogen cycle.Nature. Vol. 451 (2008) No. 7176, p. 293-296.

[3]Wang HJ, Liang XM, Jiang $\mathrm{PH}$, et al. TN:TP ratio and planktivorous fish do not affect Nutrient-chlorophyll relationships in shallow lakes. Freshwater Biology. Vol.53 (2008) No.12, p. 935-944.

[4]Park J S, Lee C H. Removal of soluble COD by a biofilmformed on a membrane in a jet loop type membrane bioreactor. Water Research. Vol. 39 (2005) No.19, p. 4609-4622. 